\title{
The prognostic significance of preoperative leukocytosis and neutrophil-to-lymphocyte ratio in patients who underwent radical cystectomy for bladder cancer
}

\author{
Cihat Ozcan, MD; ${ }^{*}$ Onur Telli, MD; ${ }^{*}$ Erdem Ozturk, MD; Evren Suer, MD; ${ }^{*}$ Mehmet Ilker Gokce,MD;* \\ Omer Gulpinar, MD; Derya Oztuna, MD; Sumer Baltaci, MD; ${ }^{*}$ Cagatay Gogus, MD*
}

*Ankara University, School of Medicine, Department of Urology, Ankara, Turkey; ‘Ankara University, School of Medicine, Department of Biostatistics, Ankara, Turkey

Cite as: Can Urol Assoc J 2015;9(11-12):E789-94. http://dx.doi.org/10.5489/cuai.3061 Published online November 4, 2015.

\section{Abstract}

Introduction: We evaluated the prognostic effects of hematologic parameters of preoperative leukocytosis and neutrophil-to-lymphocyte ratio (NLR) in patients who underwent radical cystectomy for bladder cancer.

Methods: We retrospectively reviewed the medical records of 363 patients who underwent radical cystectomy for bladder cancer between January 1990 and June 2013. In total, 286 patients were included in the study. Age, gender, pathologic stage, lymph node involvement, preoperative hydronephrosis, histologic subtype, surgical margin status, and lymphovascular invasion were recorded for each patient. Univariate and multivariate analysis were performed to determine the prognostic value of the preoperative clinical and laboratory parameters on disease-specific survival (DSS). Additionally, the correlation between leukocytosis and other factors were evaluated.

Results: According to the univariate analysis preoperative leukocytosis and NLR were detected as negative prognostic factors on DSS. Preoperative leukocytosis, NLR, stage, lymph node involvement, histologic subtype, grade and age were independent prognostic factors for DSS, on multivariate analysis. Patients with leukocytosis had higher stage, grade and lymphovascular invasion.

Conclusions: Inexpensive, reproducible, and readily available peripheral blood count components of white blood cell count and NLR were independent prognostic factors, which can stratify DSS risks in bladder cancer patients who underwent radical cystectomy.

\section{Introduction}

Patients with high-risk non-muscle invasive and muscleinvasive urothelial carcinoma of the bladder are treated with radical cystectomy. ${ }^{1}$ However about $50 \%$ of these patients will develop distant metastases, and 5-year survival of locally advanced disease ranges from $26 \%$ to $64 \%$. $^{2,3}$ These poor survival outcomes suggest the need for a new risk stratifica- tion. New preoperative predicting models based on systemic inflammatory models have used only preoperative factors to identify oncologic outcome. ${ }^{4}$

Tumours associated with indicators of the systemic inflammatory-immunological process play critical roles in the development and progression of various cancers. ${ }^{5}$ Neutrophil count, lymphocyte count or neutrophil-to-lymphocyte ratio (NLR) can be independent prognostic and predictive systematic inflammatory markers for unfavourable survival in patients with urinary tract malignancies. ${ }^{6-9}$ Although elevated NLR and poor overall and disease-specific survival (DSS) in muscle-invasive disease have been reported, ${ }^{10}$ to date, the prognostic significance of leukocytosis in patients with bladder carcinoma treated with radical cystectomy has not yet been determined.

Therefore, we evaluated the prognostic impact of preoperative leukocytosis in patients with bladder carcinoma treated with radical cystectomy. We also evaluated the prognostic impact of possible hematologic factors, such as neutrophilia, lymphopenia and NLR, in predicting DSS.

\section{Methods}

Following institutional review board approval (IRB 15-57213), we reviewed the records of 369 patients who underwent RC between January 1990 and June 2013 at our institution. The diagnosis of bladder cancer was histologically confirmed by transurethral resection of bladder tumour (TURBT) in each patient. A genitourinary pathologist reviewed all surgical specimens and the diagnosis of urothelial or nonurothelial carcinoma of the bladder was confirmed. The indications for radical cystectomy included muscle-invasive tumours without evidence of distant metastasis (cT2-4, NX, $\mathrm{M0})$, recurrent multifocal superficial disease refractory to repeat transurethral resection with intravesical therapy, or Bacille Calmette-Guérin (BCG)-resistant carcinoma in situ. Tumours were graded according to the 1973 World Health Organization (WHO) grading system, ${ }^{11}$ and clinical T stage 
was determined according to the 2002 American Joint Committee on Cancer TNM staging system. ${ }^{12}$ We excluded patients who received neoadjuvant chemotherapy, radiation, with hematologic malignancies, without or unreachable preoperative complete blood count (CBC), with an active infection at the time of surgical intervention, and patients with prior blood transfusion or usage of drugs that may affect hematologic parameters.

A routine $\mathrm{CBC}$ test was part of the standard preoperative blood work and the analysis was performed close to the date of surgery. Patient characteristics included age, sex, preoperative white blood cell count (WBC), neutrophil and lymphocyte levels, NLR, preoperative hydronephrosis, clinical tumour stage, surgical margin status, pathologic tumour stages, tumour size, histology, presence of lymph node involvement, and lymphovascular invasion.

Categorical variables were presented as numbers and percentages, and metric variables as mean \pm standard deviation (SD) or median (minimum-maximum). To compare two groups for categorical variables, we used the chi-squared test (Fishers exact test). For each group, DSS curves were estimated according to the Kaplan-Meier survival analysis. Survival estimates between groups were compared using the log-rank test. Univariate and multivariate Cox regression analyses were performed to identify independent prognostic factors for DSS. Multivariate logistic analysis of predictors included all possible prognostic factors, such as patient age, lymph node pathological stage, histologic stage, surgical margin, tumour grade at TURBT, lymphovascular invasion, hydronephrosis, leukocyte count, neutrophil count, and NLR size. Hazard ratio (HR) with 95\% confidence intervals $(\mathrm{Cl})$ was given. All statistical analysis was performed using SPSS 11.5, $p<0.05$ were deemed statistically significant. $P$ values of 0.10 and 0.20 were used for the entry and removal criteria, respectively, in multivariate Cox regression analysis.

\begin{tabular}{|c|c|c|c|c|}
\hline Parameters & Total $(n=286)$ & $\begin{array}{c}\text { WBC } \\
\leq 11000(n=252)\end{array}$ & $\begin{array}{c}\text { WBC } \\
>11000(n=34)\end{array}$ & $p$ values \\
\hline $\mathrm{N}$ & 286 & 252 & 34 & \\
\hline \multicolumn{5}{|l|}{ Age } \\
\hline$<70$ & $240(83.9 \%)$ & $212(84.1 \%)$ & $28(82.4 \%)$ & \multirow{2}{*}{0.792} \\
\hline$\geq 70$ & $46(16.1 \%)$ & $40(15.9 \%)$ & $6(17.6 \%)$ & \\
\hline \multicolumn{5}{|l|}{ Gender } \\
\hline Male & $256(89.5 \%)$ & $225(89.3 \%)$ & $31(91.2 \%)$ & \multirow{2}{*}{1.000} \\
\hline Female & $30(10.5 \%)$ & $27(10.7 \%)$ & $3(8.8 \%)$ & \\
\hline \multicolumn{5}{|l|}{ Lymph node invasion } \\
\hline Negative & $244(85.3 \%)$ & $215(85.3 \%)$ & $29(85.3 \%)$ & \multirow{2}{*}{1.000} \\
\hline Positive & $42(14.7 \%)$ & $37(14.7 \%)$ & $5(14.7 \%)$ & \\
\hline \multicolumn{5}{|l|}{ Tumour stage } \\
\hline T0 & $32(11.2 \%)$ & $32(12.7 \%)$ & $0(0 \%)$ & \multirow{5}{*}{0.048} \\
\hline T1 & $49(17.1 \%)$ & $44(17.5 \%)$ & $5(14.6 \%)$ & \\
\hline T2 & $81(28.3 \%)$ & $70(27.8 \%)$ & $11(32.4 \%)$ & \\
\hline T3 & $73(25.5 \%)$ & $66(26.2 \%)$ & $7(20.6 \%)$ & \\
\hline $\mathrm{T} 4$ & $51(17.8 \%)$ & $40(15.8 \%)$ & $11(32.4 \%)$ & \\
\hline \multicolumn{5}{|l|}{ Histological type } \\
\hline Urothelial carcinoma & $236(82.5 \%)$ & $209(82.9 \%)$ & $27(79.4 \%)$ & \multirow{2}{*}{0.611} \\
\hline Non-urothelial carcinoma & $50(17.5 \%)$ & $43(17.1 \%)$ & $7(20.6 \%)$ & \\
\hline \multicolumn{5}{|l|}{ Surgical margin } \\
\hline Positive & $18(6.3 \%)$ & $14(5.6 \%)$ & $4(9.4 \%)$ & \multirow{2}{*}{0.247} \\
\hline Negative & $268(93.7 \%)$ & $238(94.4 \%)$ & $30(90.6 \%)$ & \\
\hline \multicolumn{5}{|l|}{ Grade } \\
\hline 3 & $190(66.4 \%)$ & $160(63.4 \%)$ & $30(83.3 \%)$ & \multirow{2}{*}{0.004} \\
\hline$\leq 2$ & $96(33.6 \%)$ & $92(36.6 \%)$ & $4(6.7 \%)$ & \\
\hline \multicolumn{5}{|l|}{ Lymphovascular invasion } \\
\hline Positive & $51(17.8 \%)$ & 39 (15.5\%) & $12(35.3 \%)$ & \multirow{2}{*}{0.005} \\
\hline Negative & $235(82.2 \%)$ & $213(84.5 \%)$ & $22(64.7 \%)$ & \\
\hline \multicolumn{5}{|l|}{ Carcinoma in-situ } \\
\hline Positive & 19 (6.6\%) & $17(6.7 \%)$ & $2(5.9 \%)$ & \multirow{2}{*}{1.000} \\
\hline Negative & 267 (93.4\%) & $235(93.3 \%)$ & $32(94.1 \%)$ & \\
\hline \multicolumn{5}{|l|}{ Preoperative hydronephrosis } \\
\hline Positive & $66(23.1 \%)$ & $56(22.2 \%)$ & $10(29.4 \%)$ & \multirow{2}{*}{0.350} \\
\hline Negative & $220(76.9 \%)$ & $196(77.8 \%)$ & $24(70.6 \%)$ & \\
\hline
\end{tabular}


NLR was analyzed as dichotomous variable according to an approximate "optimal" cut point of 2.5 obtained by a validated web-based software. ${ }^{13-16}$ Neutrophil and lymphocyte counts were defined as 1800-7700 cells/microL and 1500-4000 cells/microL, respectively, according to WHO global standards. Leukocytosis was defined as WBC $>11000$ cells/microL.

\section{Results}

Of the 363 patients, we excluded 77 patients who did not meet our inclusion criteria. In the end, we had 286 patients in our study: 256 males and 30 females. The mean $( \pm$ SD) patient age was $60.7 \pm 9.42$ years (range: $29-83$ ). The median follow-up period was 28 months (range: 0-144). Clinicopathologic characteristics for patients with and without preoperative leukocytosis did not differ in parameters of age, gender, lymph node invasion, histological type, surgical

Table 2. Univariate and multivariate Cox regression analyses of prognostic factors on disease-specific survival of 286 patients who underwent cystectomy for bladder cancer

\begin{tabular}{|c|c|c|c|c|c|c|}
\hline \multirow{2}{*}{ Parameters } & \multicolumn{3}{|c|}{ Univariate analysis } & \multicolumn{3}{|c|}{ Multivariate analysis } \\
\hline & HR & $95 \% \mathrm{Cl}$ & $p$ value & HR & $95 \% \mathrm{Cl}$ & $p$ value \\
\hline \multicolumn{7}{|l|}{ Age } \\
\hline \multicolumn{7}{|l|}{$<70^{*}$} \\
\hline$\geq 70$ & 1.648 & $1.047-2.594$ & 0.028 & 1.630 & $1.092-2.608$ & 0.042 \\
\hline \multicolumn{7}{|l|}{ Gender } \\
\hline \multicolumn{7}{|l|}{ Female } \\
\hline Male & 1.322 & $0.832-2.026$ & 0,736 & & & \\
\hline \multicolumn{7}{|l|}{ Lymph node invasion } \\
\hline \multicolumn{7}{|l|}{ Negative* } \\
\hline Positive & 3.940 & $2.623-5.919$ & $<0.001$ & 1.517 & $1.097-2.370$ & 0.030 \\
\hline \multicolumn{7}{|l|}{ Pathological stage } \\
\hline \multicolumn{7}{|l|}{$\mathrm{T} 2 \leq^{*}$} \\
\hline $\mathrm{T} 2>$ & 7.114 & $4.716-10.730$ & $<0.001$ & 5.463 & $3.469-8.606$ & $<0.001$ \\
\hline \multicolumn{7}{|l|}{ Histologic type } \\
\hline \multicolumn{7}{|l|}{ Urothelial carcinoma } \\
\hline Non-urothelial carcinoma & 2.116 & $1.428-3.136$ & $<0.001$ & 1.533 & $1.020-2.305$ & 0.040 \\
\hline \multicolumn{7}{|l|}{ Surgical margin } \\
\hline \multicolumn{7}{|l|}{ Negative* } \\
\hline Positive & 1.852 & $1.062-3.231$ & 0,026 & & & \\
\hline \multicolumn{7}{|l|}{ Grade } \\
\hline \multicolumn{7}{|l|}{ Low* $^{*}$} \\
\hline High & 4.741 & $2.864-7.848$ & $<0.001$ & 3.337 & $1.993-5.587$ & $<0.001$ \\
\hline \multicolumn{7}{|l|}{ Lymphovascular invasion } \\
\hline \multicolumn{7}{|l|}{ Negative* } \\
\hline Positive & 2.690 & $1.840-3.934$ & $<0.001$ & & & \\
\hline \multicolumn{7}{|l|}{ Carcinoma in-situ } \\
\hline \multicolumn{7}{|l|}{ Positive* } \\
\hline Negative & 1.164 & $0.920-1.487$ & 0,125 & & & \\
\hline \multicolumn{7}{|l|}{ Preoperative hydronephrosis } \\
\hline \multicolumn{7}{|l|}{ Negative* } \\
\hline Positive & 2.359 & $1.637-3.398$ & $<0.001$ & & & \\
\hline \multicolumn{7}{|l|}{ Leukocyte } \\
\hline$\leq 11000^{*}$ & & & & & & \\
\hline$>11000$ & 2.086 & $1.314-3.310$ & 0.002 & 1.773 & $1.096-2.687$ & 0.020 \\
\hline Neutrophil & & & & & & \\
\hline$<7700^{*}$ & & & & & & \\
\hline$\geq 7700$ & 1.528 & $1.023-2.283$ & 0.035 & & & \\
\hline Lymphocyte $>1500$ & & & & & & \\
\hline Lymphocyte $\leq 1500$ & 1.435 & $0.816-2.532$ & 0.691 & & & \\
\hline NLR & & & & & & \\
\hline$<2.5^{*}$ & & & & & & \\
\hline$\geq 2.5$ & 1.798 & $1.260-2.567$ & 0.001 & 1.965 & $1.042-3.586$ & 0.022 \\
\hline
\end{tabular}




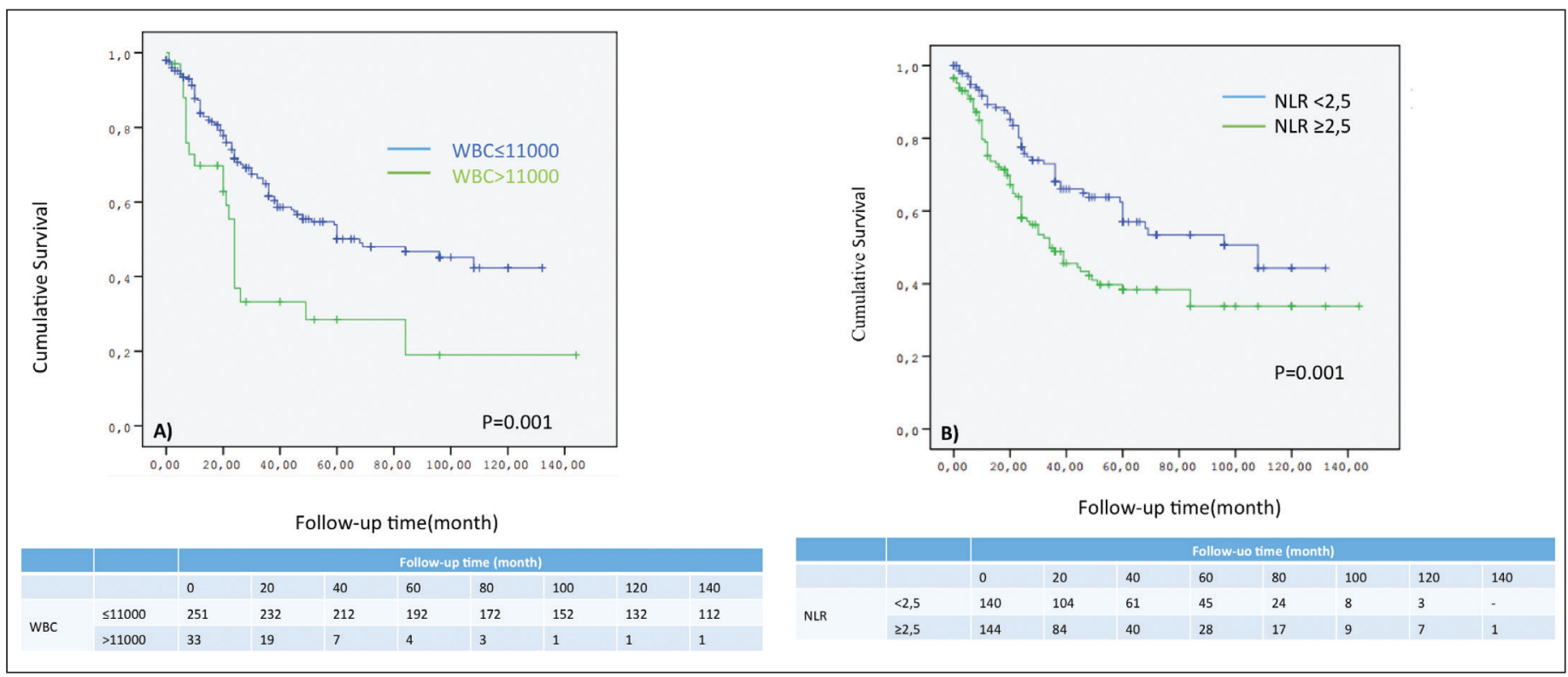

Fig. 1. A: Disease-specific survival (DSS) rates according to white blood cell (WBC) count; (B) DSS rates according to neutrophil-to-lymphocyte ratio.

margin, carcinoma in-situ or hydronephrosis $(p>0.05$ for all) (Table 1). The median time from preoperative leukocytosis and NLR to radical cystectomy was 7 days (range: $1-13)$. Patients with WBC $>11000$ had more T4 category tumours $(p=0.048), \mathrm{G} 3$ tumours $(p=0.004)$, and positive lymphovascular invasion $(p=0.005)$ (Table 1$)$.

According to Kaplan-Meier analysis, patients with the following clinicopathological characteristics had shorter survival periods: patient age $(\geq 70), p=0.028$; lymph node invasion (positive), $p<0.001$; clinical T stage (T2 ),$p<0.001$; histological type (non-transitional cell carcinoma [TCC]), $p<0.001$; surgical margin (positive), $p=0.026$; tumour grade (high), $p<0.001$; lymphovascular invasion (positive), $p<0.001$; carcinoma in-situ (negative), $p=0.125$; hydronephrosis (positive), $p<0.001$; leukocyte count $(>11000$ ), $p<0.002$; neutrophil count $(\geq 7700), p=0.035$; and NLR $(\geq 2.5), p<0.001$. DSS rates at 3 years were $49.8 \%$ and $73 \%$ for patients with a NLR $\geq 2.5$ and NLR $<2.5$, respectively; and $36.9 \%$ and $64.9 \%$ for patients with preoperative WBC $\leq 11000$ and $W B C>11000$, respectively (Fig. 1). After univariate Cox regression analysis, age $\geq 70$ (HR 1.630, $p=0.042)$, positive lymph node (HR 1.517, $p=0.030$ ), clinical T2 $>$ stage tumours (HR 5.463, $p<0.001$ ), non-TCC bladder cancers (HR 1.533, $p=0.040$ ), high-grade tumours (HR 3.337, $p<0.001$ ), preoperative leukocytosis (HR 1.773, $p=0.020)$, and NLR $\geq 2.5$ (HR 1.965, $p=0.022$ ) predicted DSS in bladder cancer patients treated with radical cystectomy according to multivariate Cox regression analysis (Table 2).

\section{Discussion}

We found that preoperative leukocytosis was associated with advanced pathologic stage at time of cystectomy, higher grade (G3) tumours, and positive lymphovascular invasion. Furthermore, both hematologic parameters of preoperative leukocytosis (WBC $>11000$ ) and NLR $\geq 2.5$ were significant predictors of DSS in patients with bladder carcinoma undergoing radical cystectomy.

Previous studies have investigated the prognostic value of pretreatment leukocytosis with gynaecologic cancers and an elevated NLR with adverse oncologic outcomes, including breast, colorectal, non-small cell lung, gastric and renal cell cancers. ${ }^{16-21}$ In general, tumours can affect hematopoietic parameters by significant tumour bleed, or by affecting hematopoiesis through infiltration into the bone marrow or by production of pro-inflammatory cytokines and free radicals that damage hematopoietic progenitor cells, as paraneoplastic syndromes. ${ }^{22}$

Recently, several studies reported an elevated NLR having similar prognostic significance in those with urothelial carcinoma. An elevated NLR before cystectomy has been associated with decreased overall and DSS. ${ }^{6-10}$ In our study, NLR was significantly associated with DSS similar to previous reports. ${ }^{6,10}$ In contrast, Demirtas and colleagues did not find a significant association between patients with an NLR $>2.5$ and overall survival. ${ }^{15}$

On the other hand, a hematopoietic parameter, leukocytosis, which may be a possible prognostic factor, has largely been limited to individual case reports of paraneoplastic syndromes within the published data on urothelial carcinoma. ${ }^{23,24}$ To the best of our knowledge, this is the first study 
to demonstrate the prognostic significance of preoperative leukocytosis in patients who underwent radical cystectomy for bladder cancer. In the present study, patients with leukocytosis had significantly shorter DSS than patients without leukocytosis. Moreover, multivariate analyses revealed that preoperative leukocytosis was independently associated with decreased DSS. Previous studies have demonstrated that hematopoietic cytokines may stimulate leukocytosis and treatment with exogenous G-CSF stimulates the growth of bladder cancer cells in vitro. ${ }^{25}$

Similar to our current study, non-hematologic parameters of our multivariate analyses variables, such as age, positive lymph node, clinical T2> stage tumours, non-TCC bladder and high-grade tumours, have been suggested as one of the significant preoperative prognostic factors. ${ }^{10,26,27}$

Our study has its limitations, including its retrospective, non-randomized nature, which may have led to a selection bias with a limited number of patients from a single institution. Additionally all possible factors were analyzed that resulted as too many variables in a multivariate analysis. A possible inflammatory condition that may have affected the hematopoietic system was not accounted for in our study. Future prospective, well-controlled clinical studies are needed to confirm the exact role of hematologic parameters and whether an abnormal hematologic profile is an end result of tumour growth or an underlying cause of mortality in this group of patients.

\section{Conclusion}

In the current study, preoperative leukocytosis was associated with T4 category, tumour grade of 3 and positive lymphovascular invasion in patients with bladder carcinoma treated with radical cystectomy. Furthermore, both peripheral blood count components of an elevated NLR $>2.5$ and preoperative leukocytosis were significant predictors of worsened DSS. Further prospective studies in multiple institutions with larger cohorts are required to validate these findings.

Competing interests: The authors declare no competing financial or personal interests.

This paper has been peer-reviewed.

\section{References}

1. Faba OR, Palou J, Breda A, et al. High-risk non-muscle-invasive bladder cancer: Update for a better identification and treatment. World J Urol 2012;30:833-40. http://dx.doi.org/10.1007/s00345-012-0967-1

2. Malkowicz SB, van Poppel H, Mickisch G, et al. Muscle-invasive urothelial carcinoma of the bladder. Urology 2007;69:3-16. http://dx.doi.org/10.1016/j.urology.2006.10.040

3. Stein JP, Lieskovsky G, Cote R, et al. Radical cystectomy in the treatment of invasive bladder cancer: Long-term results in 1,054 patients. J Clin Oncol 2001;19:666-75.
4. Wei Y, Jiang YZ, Qian WH. Prognostic role of NLR in urinary cancers: A meta-analysis. PLoS One 2014;9:e92079. http://dx.doi.org/10.1371/journal.pone.0092079

5. Mantovani A, Allavena P, Sica A, et al. Cancer-related inflammation. Nature 2008;454:436-44. http:// dx.doi.org/10.1038/nature07205

6. Gondo T, Nakashima J, Ohno Y, et al. Prognostic value of neutrophil-to-lymphocyte ratio and establishment of novel preoperative risk stratification model in bladder cancer patients treated with radical cystectomy. Urology 2012;79:1085-91. hitp://dx.doi.org/10.1016/i.urology.2011.11.070

7. Mano R, Baniel J, Shoshany 0 , et al. Neutrophil-to-lymphocyte ratio predicts progression and recurrence of non-muscle-invasive bladder cancer. Urol Oncol 2015;33:67.el-7. http://dx.doi.org/10.1016/j. urolonc.2014.06.010

8. Potretzke A, Hillman L, Wong K, et al. NLR is predictive of upstaging at the time of radical cystectomy for patients with urothelial carcinoma of the bladder. Urol Oncol 2014;32:631-6. http://dx.doi. org/10.1016/i.urolonc.2013.12.009

9. Kaynar M, Yildrim ME, Badem H, et al. Bladder cancer invasion predictability based on preoperative neutrophillymphocyte ratio. Tumor Biol 2014;35:6601-5. http://dx.doi.org/10.1007/s13277-014-1889-x

10. Viers BR, Boorijan $S A$, Frank I, et al. Pretreatment neutrophil-to-lymphocyte ratio is associated with advanced pathologic tumor stage and increased cancer-specific mortality among patients with urothelial carcinoma of the bladder undergoing radical cystectomy. Eur Urol 2014;66:1157-64. http://dx.doi. org/10.1016/i.eururo.2014.02.042

11. Epstein Jl, Amin MB, Reuter VR, et al. The World Health Organization/International Society of Urological Pathology consensus classification of urothelial (transitional cell) neoplasms of the urinary bladder. Bladder Consensus Conference Committee. Am J Surg Pathol 1998;22:1435-48. http://dx.doi. org/10.1097/00000478-199812000-00001

12. Sobin LH, Wittekind C. International Union against Cancer, TNM: Classification of Malignant Tumors. New York, NY; 2002:xxiii:(239p).

13. Budczies J, Klauschen F, Sinn BV, et al. Cutoff Finder: A comprehensive and straight forward Web application enabling rapid biomarker cut off optimization. PLoS One 2012;7:51862. http://dx.doi. org/10.1371/journal.pone.0051862

14. Atzpodien J, Royston P, Wandert $T$, et al. Metastatic renal carcinoma comprehensive prognostic system. Br J Cancer 2003;88:348-53. http://dx.doi.org/10.1038/si.bjc.6600768

15. Demirta A, Sabur V, Akınsal EC, et al. Can neutrophil-lymphocyte ratio and lymph node density be used as prognostic factors in patients undergoing radical cystectomy? ScientificWorldJournal 2013;31:703579. http://dx.doi.org/10.1155/2013/703579

16. Krane $\mathrm{LS}$, Richards KA, Kader AK, et al. Preoperative neutrophil/lymphocyte ratio predicts overall survival and extravesical disease in patients undergoing radical cystectomy. J Endourol 2013;27:1046-50. http:// dx.doi.org/10.1089/end.2012.0606

17. So KA, Hong JH, Jin HM, et al. The prognostic significance of preoperative leukocytosis in epithelial ovarian carcinoma: A retrospective cohort study. Gynecol Oncol 2014;132:551-5. http://dx.doi.org/10.1016/i. ygyno.2014.01.010

18. Azab B, Bhatt VR, Phookan J, et al. Usefulness of the neutrophil-to lymphocyte ratio in predicting shortand long-term mortality in breast cancer patients. Ann Surg Oncol 2012;19:217-24. http://dx.doi. org/10.1245/s10434-011-1814-0

19. Ishizuka $M$, Nagata H, Takagi K, et al. Combination of platelet count and neutrophil to lymphocyte ratio is a useful predictor of postoperative survival in patients with colorectal cancer. BrJ Cancer 2013;109:401-7. http://dx.doi.org/10.1038/bic.2013.350

20. Sarraf KM, Belcher E, Raevsky E, et al. Neutrophil/lymphocyte ratio and its association with survival after complete resection in non-small cell lung cancer. J Thorac Cardiovasc Surg 2009;137:425-8. http:// dx.doi.org/10.1016/i.jtcvs.2008.05.046

21. Yamanaka T, Matsumoto $S$, Teramukai $S$, et al. The baseline ratio of neutrophils to lymphocytes is associated with patient prognosis in advanced gastric cancer. Oncology 2007;73:215-20. http://dx.doi. org/10.1159/000127412

22. Chen $Y$, Zhang $L$, Liu WX, et al. Prognostic significance of preoperative anemia, leukocytosis and thrombocytosis in Chinese women with epithelial ovarian cancer. Asian Pac J Cancer Prev 2015;16:933-9. http://dx.doi.org/10.7314/APJCP.2015.16.3.933

23. Dukes JW, Tierney LM Jr. Paraneoplastic leukemoid reaction as marker for transitional cell carcinoma recurrence. Urology 2009;73:17-9. http://dx.doi.org/10.1016/j.urology.2008.05.023

24. Izard JP, Gore JL, Mostaghel EA, et al. Persistent, unexplained leukocytosis is a paraneoplastic syndrome associated with a poor prognosis in patients with urothelial carcinoma. Clin Genitourin Cancer 2015;13:e253-8. http://dx.doi.org/10.1016/j.clgc.2015.02.008

25. Shameem IA, Kurisu H, Matsuyama $\mathrm{H}$, et al. Direct and indirect effects of recombinant human granulocytecolony stimulating factor on in vitro colony formation of human bladder cancer cells. Cancer Immunol Immunother 1994;38:353-7. http://dx.doi.org/10.1007/BF01517203 
Ozcan et al.

26. Girgin C, Sezer A, Uc R, et al. Outcome of the treatment of invasive non-transitional cell carcinoma. Int J Urol 2003;10:525-9. http://dx.doi.org/10.1046/j.1442-2042.2003.00679.x

27. Thrasher JB, Frazier HA, Robertson JE. Clinical variables which serve as predictors of cancer-specific survival among patients treated with radical cystectomy for transitional cell carcinoma of the bladder and prostate. Cancer 1994;73:1708-15. http://dx.doi.org/10.1002/1097-0142(19940315)73:6<1708::AlDCNCR2820730626>3.0.C0;2-J
Correspondence: Dr. Onur Telli, Ankara University School of Medicine Department of Urology, Sihhiye/Ankara, 06100 Turkey; onurtelli@yahoo.com 